\title{
Significance of Crime Scene Visit by Forensic Pathologist in Cases of Atypical Firearm Injuries.
}

\author{
Thejaswi HT, Kumar A, Krishna K
}

Department of Forensic Medicine \& Toxicology

All India Institute of Medical Sciences

New Delhi, India - 110029

Corresponding Author

Thejaswi H T

Department of Forensic Medicine \& Toxicology

All India Institute of Medical Sciences

New Delhi, India - 110029

E-mail: thejaswiht@gmail.com

\section{Citation}

Thejaswi HT, Kumar A, Krishna K. Significance of Crime Scene Visit by Forensic Pathologist in Cases of Atypical Firearm Injuries. Kathmandu Univ Med J 2015;51(3):274-8.

\begin{abstract}
Deaths due to firearms are some of the interesting and contentious cases that a forensic pathologist/autopsy surgeon encounters in his practice. Whenever there is 'ambiguity' regarding the nature or sequence of events any unnatural deaths including those caused by firearms the practice of visiting crime scene should be encouraged especially in a country like India where autopsy surgeons often neglect it. Here we present a case report in which there were inconsistencies in the autopsy findings with the alleged history. The witnesses heard about four to six gunshot sounds, whereas only two spent cartridge cases were retrieved from the crime scene. Authors identified the atypical nature of firearm injuries sustained by the victims that were possible by just two bullets. Crime scene visit was undertaken where we discovered the possibility of the echo effect behind the production of four to six sounds. Further by using computer software program, positions of the gunman, victims and the bullet trajectory of the two bullets was created.
\end{abstract}

\section{KEY WORDS}

Atypical firearm wounds, crime scene, echo effect, re-entry firearm wound, wound track.

\section{INTRODUCTION}

Firearm injuries are among the interesting and contentious cases that a forensic pathologist/autopsy surgeon encounters in his practice. Furthermore, firearm deaths which involve multiple gunmen and victims pose complex challenges to not only forensic pathologists, but also to law enforcement officials. In a country like India which has the notorious distinction of having second the largest 'civilian-owned' firearms in the world highlights this concern. ${ }^{1}$ Further the issue is complicated by the fact that most of these 'civilian-owned' firearms are 'unlicensed and illegal' in nature and are being recklessly used by the trigger happy criminals. As per a report published in 2011, the total estimated civilian owned firearms in the whole world is about $650,000,000$ out of which India accounts for approximately $40,000,000$, second only to United States. What is more intriguing is that out of these just $6,300,000$ or $15.75 \%$ are 'licensed' firearms, the rest overwhelming $33,700,000$ are 'unlicensed illegal guns' which are rampantly used by criminals. ${ }^{2}$ The situation becomes further complicated by the lack of credible witnesses and material evidence like CCTV footage, etc.

Time and again atypical firearm injuries have baffled medical and police personnel. ${ }^{3}$ Forensic pathologists are expected to recognize 'atypical firearm wounds' and must be aware of the implications, requirements, and pitfalls in interpretation of these injuries so that the correct understanding not only provides valuable information that can assist law enforcement in their investigation but also is essential for the final determination of manner of death. ${ }^{4}$ Visiting the crime scene involving suspicious deaths is not only desirable but an essential part of the investigation of a sudden or suspicious deaths. ${ }^{5}$ Unfortunately it is not mandatory in India to visit scene of crime by pathologist/ autopsy surgeon. This case report highlights the importance of crime scene visit by the autopsy surgeon especially while dealing with atypical firearm injuries and also whenever there is 'ambiguity' regarding the nature or sequence of events related to firearm deaths. 


\section{CASE REPORTS}

A 17 years old girl and her mother (aged about 35 years) were shot dead by a man after the girl objected for urinating near the entrance of her home. Both the girl and her mother were immediately rushed to Emergency of level one Trauma care center. On arrival at the emergency section, the girl had multiple gunshot wounds on her right upper chest, right arm and right palm. She was in the state of shock with absence of pulse, blood pressure and respiration. The pupils were dilated and were sluggishly reacting to the light. Immediately the patient was shifted to the operation theatre where Campshell thoracotomy and open cardiac massage was performed. Two large rents in the heart over the right and left ventricle were seen which were repaired. During the process she developed repeated cardiac arrest and in spite of the best efforts could not be revived and died on the operation table. The dead body was preserved in cold storage for Medico legal autopsy. Meanwhile her mother who had sustained, one gunshot wound on the lateral aspect of the right side of the abdomen without any exit wound was stabilized but before she could provide any statement, her condition deteriorated and was immediately shifted to Major Operation Theatre. Radiological investigations revealed the presence of a single bullet in the left hemi-pelvis (Fig 1a-b).

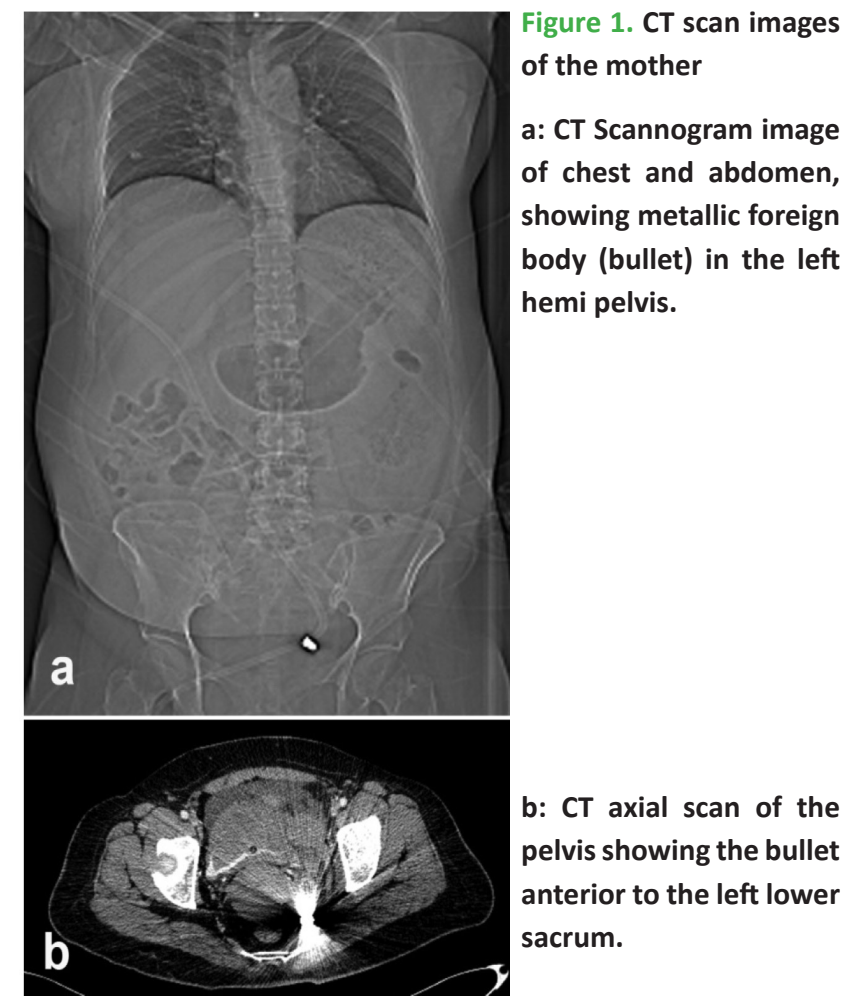

Soon after the incident police personnel visited the scene of crime and began their investigation by questioning the neighbors. It was found that the assailant after being objected to his urination, returned with a hand held firearm along with another accomplice and fired multiple times at the girl and her mother. There were inconsistencies in the statements recorded by the neighbors regarding number of shots fired, which ranged from four to six in quick succession of different intensities. The Crime Scene Investigation (CSI) team from the police visited the spot and could recover two spent cartridge cases. With the preliminary reports suggesting multiple firearm injuries to both mother and daughter along with the statements from the neighbors in the locality, the police assumed that he must have shot more than twice and they continued to screen the area for more spent cartridge cases. In addition to this since neighbors heard gunshot with different intensities, the possibility of the involvement of the second gunman with another firearm was not ruled out. Medico legal autopsy was carried out on the dead body of the girl on the following day of the incident.

\section{Autopsy findings:}

Body was wrapped with hospital gown. Rigor mortis was present all over the body. Postmortem staining was present and fixed on the back except for contact areas and no putrefaction changes were present. Horizontally placed surgically stapled wound of Campshell thoracotomy was present on the front of the chest.

\section{Examination of the injuries:}

1) Firearm entry wound, oval shaped, measuring $2.2 \times 1.8$ $\mathrm{cms}$, surrounded by reddish colored abrasion ring, was present on the back of the right wrist, just below the styloid process of the radius, $98 \mathrm{cms}$ from the right heel. It was surrounded by a zone of powder tattooing in the form of reddish colored punctate abrasions over an area of $15 \times 4$ $\mathrm{cms}$ and the direction of the wound track being forwards and outwards.

2) Stellate shaped firearm exit wound measuring $2.4 \times 1.9$ cms, with everted margins was present on the thenar aspect of the right palm, $1.5 \mathrm{cms}$ below the wrist joint with fracture of underlying metacarpal bone.

3) Firearm entry wound measuring $1.9 \times 1.8 \mathrm{cms}$, oval shaped, surrounded by reddish colored abrasion ring, was present on the lateral aspect of the right arm, $14 \mathrm{cms}$ above the lateral epicondyle and $129 \mathrm{cms}$ from the right heel. It was surrounded by the zone of powder tattooing in the form of reddish colored punctate abrasions over an area of $16 \times 4 \mathrm{cms}$. The direction of the wound track was medially, downwards and forwards.

4) Firearm exit wound, measuring $1.3 \times 0.9 \mathrm{cms}$ was present on the medial aspect of the right arm, $12 \mathrm{cms}$ above the medial epicondyle and $127 \mathrm{cms}$ from the right heel, in continuation of the wound track of the injury no 3.

5) Firearm 're-entry' wound measuring $1.1 \times 0.8 \mathrm{cms}$ was present on the lateral aspect of the right breast, $21 \mathrm{cms}$ from midline, $15 \mathrm{cms}$ below the right clavicle and $127 \mathrm{cms}$ from the right heel. It was surrounded by an area of reddish colored abrasion ring. No tattooing or blackening was present. On exploration of the wound track it was directed 
medially and slightly to the lower side, penetrating the $4^{\text {th }}$ intercostal space, traversing anterior aspect of the middle lobe of the right lung, further penetrating the right ventricle and the partially deformed semi-jacketed bullet measuring $1.3 \times 0.7 \mathrm{cms}$ was found embedded in the inter-ventricular septum. About $180 \mathrm{ml}$ of clotted blood was present in the right pleural cavity, $100 \mathrm{ml}$ in the pericardial cavity and 160 $\mathrm{ml}$ in left pleural cavity. The cause of death was opined as, 'shock' due to high velocity 'intermediate range' gunshot wound to the chest.

Since there were many discrepancies in the history and autopsy findings, a crime scene visit was undertaken to get more clarity on the matter. Specific issues which needed to be clarified were

a) Explaining the multiple gunshot wounds present in the victims in relation to each other.

b) Understand why neighbors heard about 4-6 gunshot sounds.

c) Since the neighbors heard gunshot sounds with varying intensities, explore the possibility of the second gunman.

d) Reconstruct the sequence of events.

\section{Crime Scene visit}

The crime took place in a basti (shantytown) which is thickly a populated urban area characterized by crowding, dirty run-down housing marked by poverty and social disorganization. Before one can reach the scene of crime, he has to pass through congested area where one had to use the passage which runs through the houses as small chain of tunnels barely enough to fit two people at a time (Fig.2a). From one of such passages, we had to take the staircase where the accused had allegedly been urinating (Fig. 2b) to reach the house that was located on the first floor, where the crime took place. It was almost 18 hours since the incident and crime scene was already processed by CSI wing of the Police. After arriving at the house, a methodical approach was undertaken to process the crime scene. An initial walk-through of the area was carried out to identify the limits of the crime scene along with the CSI team.

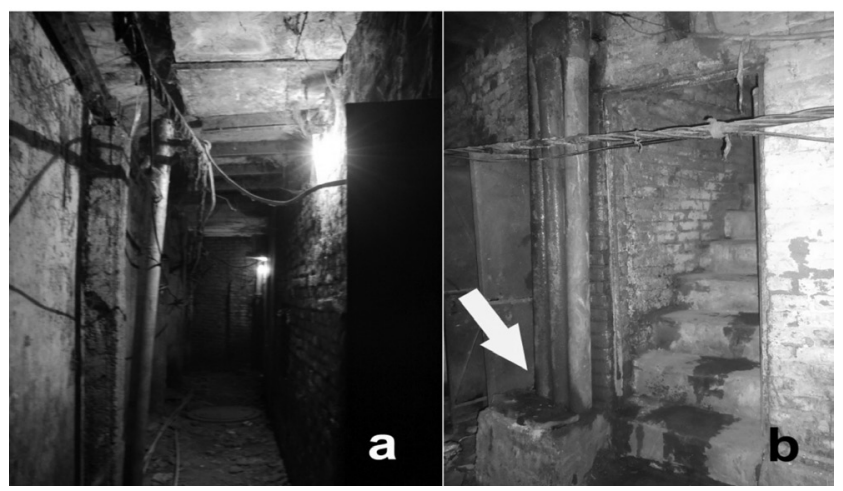

Figure 2. a: Tunnel- like passage leading to the crime scene b: The spot where the accused was allegedly urinating, leading to the conflict.
Witnesses who reached immediately after the incident were interviewed.

a) It was stated that no other person was present other than the gunman, his accomplice and the two victims when the incident took place.

b) They described the relative positions of the mother and daughter when they were found before they were rushed to the hospital. Allegedly after being shot, the girl collapsed over her injured mother's arms, who held her while screaming for help.

c) When asked specifically about the number of shots heard by them, they could recollect hearing more than twice of different intensities at quick intervals.

d) The CSI team of the police had already recovered two brass cartridge cases and they explained their location in the scene from where it was found.

e) We again searched the room with the 'grid search' method. In-spite of all their efforts no more cartridge case(s) were found.

Now we started to look for possible explanations as to why the neighbors heard multiple gunshots at quick succession and to explore the possibility of the second gunman.

Since the whole area was bustling with strangers, street dogs were barking randomly and these barking sounds were being echoed; we proposed the possibility of similar 'echo effect' for reason behind hearing multiple gunshots by the neighbors. To get a decisive answer a small firecracker was ignited in the scene and authors along with police personnel stood at the different places where the neighbors were present at the time of the incident. Although only one firecracker was detonated, authors clearly heard two explosion sounds in quick succession, the second one being in diminished intensity. The same was heard by the other observers in their respective locations. The exercise was repeated which yielded consistent results.

\section{DISCUSSION}

It is important for the forensic pathologist to have necessary training in recognizing various types of atypical gunshot wounds. By being atypical, they have an uncharacteristic appearance which to the untrained eyes can lead to misinterpretation and erroneous conclusion.

1. Intermediary objects: Intermediary objects modify the features to a very large extent. If the bullet strikes objects such as thick clothing, jewelry, furniture, windowpanes, etc., the firearm entry wound will be atypical as well as additional injuries produced by the intermediary objects will be present. ${ }^{6}$ This type of atypical wound was sustained by the mother in our case. One of the bullets after striking the posterior aspect of the palm of the girl had exited from the thenar side, proceeded further and stuck the abdomen of the mother. Here intermediary object being the 
daughter's hand (Fig 3a). Also, if a person when fired upon is standing behind windowpanes, after the bullet strikes the glass sheet, it will lose its gyroscopic stability leading to considerable yawing and tumbling thus producing atypical entry wounds. Simultaneously there will be additional lacerations/stippling caused by the shattered glass pieces. ${ }^{7}$
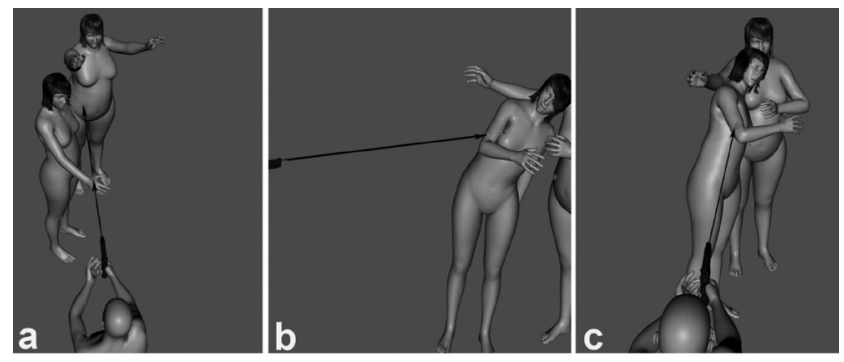

Figure 3. Relative positions of the gunmen and victims (reconstructed by DAZ 3D software)

(a) Trajectory of the bullet striking the hand of the girl before it hits the abdomen of mother, $(b, c)$ Trajectory of the solitary bullet causing firearm re-entry wounds in the girl.

2. Re-entry gunshot wound: This occurs when the bullet/ projectile enters one part of the body, exits after traversing it completely, only to re-enter into another part of the body. This most commonly occurs when the bullet strikes the arms from the lateral sides, crisscrosses it and exits from the medial side then re-enters the thorax. Such re-entry wound may or may not have basic features of firearm entry wound and may be oval or slit shaped, with or without abrasion ring. Thus with the single bullet/projectile, more than one entry wound can occur. ${ }^{7}$ This type of atypical wound was seen in one of the victims (daughter) in this case. One of the bullet had struck her outer aspect of the right arm, traversed her arm, exited from the medial side only to reenter her right lateral aspect of chest resulting in re-entry gunshot wound (Injury nos. 3-5). It was demonstrated that Injury nos. 3-5 were in same trajectory (Fig 3b and 3c)

3. Graze wounds: Here the bullet/projectile strikes the body in a tangential angle injuring the superficial part of the body leading to laceration across the wound track. The important point to be noted here is that the resultant skin tags point towards the opposite direction of the projectile. In other words if the bullets passes from left to right, the skin tags will point to the left side. ${ }^{8}$

4. Ricochet wounds: Here the bullet first strikes a hard surface at an angle after which it bounces back to hit the body. Since the projectile after hitting the rough surface gets deformed, the entry wound thus produced shall be irregular and at times multiple due to fragmentation of the bullets or surface material on which the bullet ricochets. This appearance may be mistaken for gunpowder 'tattooing' abrasions, but they are usually larger, irregular, and coarser than true tattooing. ${ }^{9}$
5. 'Shored-up/supported' exit wound: Here the bullet after traversing the body which is supported or reinforced by a firm surface on the other side, as it exits, the everted margins of the exit wound will be rubbed against the firm supporting surface, resulting in the development of abrasion ring in its margins which is a cardinal feature of entry wound Shored exits are sometimes extremely difficult to distinguish from entry wounds when it is cold and many layers of clothing are worn - but then the situation should be clear from an examination of the clothing. ${ }^{10}$

6. If someone is killed by a handgun with a pillow firmly squeezed between the muzzle and the body, the entrance would by all means display features of distant wound rather than near-contact one. This is because the fillings in the pillow will absorb powder-soot, partially burnt and unburnt powder and gases, thus the very ingredients that produces pathognomonic features that help us classify its range will be eliminated to a large extent (further depending upon the type of firearm and the make of pillow).

Thus the autopsy surgeon should be well aware of atypical firearm wounds in its various forms and to get a holistic picture in such conflicting cases must undertake crime scene assessment. We could reconstruct the sequence of events only after thoroughly assessing the crime scene and corroborating the injuries sustained by the mother and daughter, with the relative position of them at the scene of crime. Thus it was concluded that all the injuries sustained by both mother and daughter were inflicted by just two bullets.

Regarding the reason behind the production of more than two gunshot sounds heard by the neighbors, the author suggested the possibility of echo effect being the prime reason because the whole colony being a closed area with 'no roof', with the passages being lined by brick wall crisscrossing the colony.

\section{CONCLUSION}

Whenever the forensic pathologist come across any inconsistencies in history and findings, it is advisable for him to undertake crime scene visit; unfortunately what we lack at present. In present case report without visiting the scene of crime, it would have been impossible to envisage the role of echo behind speculation of the number of shots fired and the speculations regarding the presence of second gunman were laid to rest. After three days the mother being the sole eye- witness, was fit to record detailed statement which were consistent with our observations and thus the our findings were established. 


\section{REFERENCES}

1. Karp A. Guns and the City. Small Arms Survey 2007. Cambridge: Cambridge University Press.; 2007. p. 47.

2. Kohli A, Karp A, Sonal M. Mapping Murder: The Geography of Indian Firearm Fatalities. The India Armed Violence Assessment: A Issue Brief. 2011;2:12.

3. De Giorgio F, Rainio J. Two entrances, one exit--an atypical shotgun injury: a case report. Medicine, science, and the law. 2007 Oct;47(4):353-6. PubMed PMID: 18069544. Epub 2007/12/12. eng.

4. Denton JS, Segovia A, Filkins JA. Practical Pathology of Gunshot Wounds. Archives of Pathology \& Laboratory Medicine. 2006 2006/09/01;130(9):1283-9.

5. Payne-James. J, Busuttil A, William S. Forensic Medicine: Clinical and Pathological Aspects. $1^{\text {st }}$ ed. London: Cambridge University Press; 2003. $51 \mathrm{p}$
6. Dodd MJ, Byrne K. Terminal ballistics : a text and atlas of gunshot wounds. Boca Raton, FL: CRC Taylor \& Francis; 2006. 212 p. p.

7. Vincent J. M DMD. Gunshot Wounds: Practical Aspects of Firearms, Ballistics, and Forensic Techniques. $2^{\text {nd }}$ ed: CRC Pr I Llc; 1999. 407p.

8. Dolinak D, Matshes EW, Lew EO. Forensic pathology : principles and practice. Amsterdam ; Boston: Elsevier/Academic Press; 2005. 171-2 p.

9. Payne-James J. Encyclopedia of forensic and legal medicine. $1^{\text {st }}$ ed. Amsterdam; Boston: Elsevier Academic Press; 2005. 277-8 p.

10. The Pathology of Trauma. 3 ed. Mason J, Purdue B, editors. London, England: Arnold/Hodder Group; 2000. 516 p. 